\title{
CÂNCER DE MAMA: SENTIMENTOS E PERCEPÇÕES DAS MULHERES MASTECTOMIZADAS
}

\author{
BREAST CANCER: FEELINGS AND PERCEPTIONS OF WOMEN WHO HAVE \\ UNDERGONE MASTECTOMY
}

\author{
Marcia Luiza Ferreira Cavalcante ${ }^{a}$, Fernanda Chaves ${ }^{b}$, Arlene Laurenti Monterrosa Ayala ${ }^{c}$ \\ amarcialuizafc@gmail.com, bfernandachaves.23@gmail.com, calayala@bol.com.br \\ Associação Educacional Luterana Bom Jesus - Joinville (SC), Brasil
}

Data de recebimento do artigo: 30/11/2015

Data de aceite do artigo: 04/04/2016

\section{RESUMO}

Introduçáo: A necessidade de evidenciar as influências da mastectomia na vida afetiva e social da mulher com câncer de mama é uma estratégia viável para intervir positivamente na assistência em saúde. Objetivos: Caracterizar as mulheres portadoras de câncer de mama que frequentam o grupo de apoio na Rede Feminina de Combate ao Câncer em Joinville (SC), e conhecer o significado da mastectomia para essas mulheres. Metodologia: Trata-se de um estudo descritivo que entrevistou 10 mulheres mastectomizadas. A coleta de dados foi realizada por meio de um questionário semiestruturado, e os dados investigados foram relacionados às características sociodemográficas e reprodutivas, a questóes emocionais e ao conhecimento que as mulheres detinham sobre o câncer de mama. Resultados: A maioria das mulheres investigadas tinha idade entre 40 a 50 anos, eram casadas, com baixa escolaridade e renda. Os sentimentos percebidos foram tristeza, angústia, revolta pela mutilação, medo da morte, vergonha, fé e esperança. A confirmação do diagnóstico de câncer trouxe profundas mudanças na vida de cada uma das mulheres. As novas formas de enfrentamento da vida expressaram-se nas expectativas voltadas para cura e na necessidade de apego religioso. Conclusóes: Evidenciaram-se, por um lado, muitas dificuldades vivenciadas pelas mulheres mastectomizadas, como o comprometimento da sua autoimagem, a dor, as dificuldades físicas e a tristeza com a retirada da mama. Por outro, revelaram sentimentos esperançosos gerados pelo amparo de familiares e pelo convívio com outras mulheres no grupo de apoio.

Palavras-chave: Neoplasias da mama, mastectomia, emoçóes.

\section{ABSTRACT}

Introduction: The need to demonstrate the influences of mastectomy in affective and social life of women with breast cancer is a viable strategy for a positive act in healthcare. Objectives: To characterize women with breast cancer who attend the support group at the Women's Network Against Cancer in Joinville, Santa Catarina, Brazil, and to know the meaning of mastectomy for these women. Methodology: This is a descriptive study that interviewed 10 women who undergone mastectomy. Data collection was performed using a structured questionnaire, and the data investigated were related to sociodemographic and reproductive characteristics, emotional issues and knowledge that women held about breast cancer. Results: Most of the surveyed women were between 40-50 years, married, with low education and income. The feelings perceived were sadness, anguish, revolt caused by the breast removal, fear of death, shame, faith and hope. The cancer diagnosis confirmation brought profound changes in the life of each woman. New ways of confronting life were expressed in the expectations focused on healing and the need for religious affiliation. Conclusions: During the research, many difficulties experienced by women after mastectomy were evident; for example, problems with their self-image, pain, physical difficulties and sadness caused by the breast removalof. On the other hand, they revealed hopeful feelings, generated by their family support and their acquaintanceship with other women from the support group.

Keywords: Breast neoplasms, mastectomy, emotions. 


\section{Introdução}

O câncer é uma das maiores causas de mortalidade e morbidade no mundo, com mais de 10 milhóes de casos novos e mais de 6 milhóes de mortes por ano. O câncer de mama é uma neoplasia maligna, que se forma a partir da proliferação incontrolável de células anormais que surgem por causa de alteraçóes genéticas, sejam elas adquiridas por hereditariedade ou por exposições ambientais ${ }^{1}$. No Brasil, o câncer de mama é mais prevalente no sexo feminino, acometendo prioritariamente mulheres com idade entre 40 e 69 anos, sendo a maior causa de morte 2 .

Em 2014, eram esperados no Brasil 57.120 casos novos de câncer de mama, com um risco estimado de 56,09 casos a cada 100 mil mulheres. Sem considerar os tumores de pele não melanoma, esse tipo de câncer é o mais frequente nas mulheres das regiốes Sudeste (71,18/100.000 hab.), Sul (70,98/100.000 hab.), Centro-Oeste (51,30/100.000 hab.) e Nordeste $(36,74 / 100.000$ hab.). Na região Norte, é o segundo tumor mais incidente: $21,29 / 100.000 \mathrm{hab}^{3}$.

O tratamento para o câncer de mama é composto basicamente pela cirurgia e por terapias adjuvantes, como a quimioterapia, a radioterapia e a hormonioterapia. Geralmente, associam-se duas ou mais terapêuticas, respeitando-se as características clínicas e psicológicas da paciente, para obter uma melhor qualidade de vida após o tratamentó .

A mastectomia é a principal terapêutica cirúrgica em razão da maior incidência de tumores avançados. Consiste na remoção radical de toda a glândula mamária associada ao esvaziamento axilar, que pode ser completo ou não ${ }^{2}$. No entanto, retirar totalmente a mama traz um estigma para a mulher, em razão de sentimentos e emoçôes muitos fortes que vêm à tona, pois, além de estar associado à morte, afeta a parte de seu corpo que simboliza sua feminilidade, interferindo na sua autoimagem, na vida sexual e na amamentação ${ }^{5}$.

Rosa e Radünz ${ }^{6}$ referem que a mama para a mulher é considerada parte fundamental de seu corpo, e que quando a mulher descobre o câncer de mama, sua identidade é questionada, o retrato dos seios exalta a beleza do corpo da mulher. Com o câncer, a mulher se considera incapaz de se sentir bela e, muitas vezes, não adere ao tratamento. Enfim, as mulheres afetadas pela doença encontram-se frágeis, e seu psicológico passa pelas fases de negação, de barganha e, finalmente, de aceitação, o que dificulta o tratamento imediato após o diagnóstico.

Os aspectos emocionais nas mulheres mastectomizadas ocasionam o aumento da incidência de óbitos entre as mulheres, em razão da desestruturação no convívio familiar e social. Os sentimentos mais citados pelas mulheres são o medo, a dor e a preocupação com o tratamento e com o que pode ser alterado em sua vida e em sua feminilidade. Sobre esses aspectos, cabe ressaltar a necessidade do apoio social e do profissional da saúde na assistência integral, visando à melhor qualidade de vida e à diminuição da angústia e do sofrimento exposto pelo trauma do diagnóstico do câncer de mama ${ }^{7}$.

Diante do exposto, a necessidade de evidenciar as influências da mastectomia na vida afetiva e social da mulher é uma estratégia viável para intervir positivamente na assistência em saúde em oncologia, dado que muitas vezes o emocional feminino é pouco considerado pelos próprios profissionais de saúde, que ressaltam mais os aspectos físicos e biológicos da mulher. Nesse sentido, espera-se que o resultado deste estudo sirva de norte, conhecimento e sensibilizaçáo por parte dos profissionais e estudantes de saúde, para que despertem sobre a importância e relevância de se trabalharem os sentimentos e as preocupaçóes da mulher mastectomizada como forma de garantir uma melhor atenção em saúde, acolhimento e cuidado da mulher acometida por essa neoplasia.

Por fim, considerando a relevância do assunto, este estudo busca conhecer, por meio da aplicação de um questionário semiestruturado, as características socioeconômicas e reprodutivas, e as relacionadas a questôes emocionais da mulher mastectomizada que participa do grupo de apoio às mulheres com câncer de mama da Rede Feminina de Combate ao Câncer em Joinville/SC.

\section{Metodologia}

Este é um estudo descritivo realizado em 2015 com 10 mulheres portadoras de câncer de mama, submetidas à mastectomia, e que participam do grupo Rosa Mulher na Rede Feminina de Combate ao Câncer de Joinville/SC.

Joinville é o município mais populoso de Santa Catarina e o terceiro da região Sul. Situa-se na região nordeste do estado, com população de 554.601 habitantes em 2014. Sua região metropolitana é constituída pelos municípios adjacentes que formam a Região Metropolitana do Norte/Nordeste Catarinense. A região produz $18,9 \%$ do Produto Interno Bruto (PIB) global de Santa Catarina, e a cidade é o terceiro maior polo industrial da região Sul do Brasil. O município possui um dos mais altos índices de desenvolvimento humano (IDH) entre os municípios brasileiros (0.857), ocupando a décima terceira posição nacional e a quarta entre os municípios catarinenses ${ }^{3}$.

A razão pela qual escolhemos as mulheres mastectomizadas se deve ao fato que estudos têm demonstrado que a amputaçáo da mama fragiliza a mulher, suscita sentimentos de perda e produz alteraçóes importantes na imagem corporal e na autoimagem da mulher, 
trazendo-lhe muito sofrimento e afetando de maneira importante sua relação com a vida ${ }^{8}$.

A escolha da amostra ocorreu por conveniência, e a participação dessas mulheres se sucedeu por meio de um convite individual, fazendo parte da investigação aquelas 10 primeiras mastectomizadas, de um total de 28 , que aceitaram colaborar com o estudo, na condição de informante, por meio da assinatura do Termo de Consentimento Livre e Esclarecido (TCLE). Esta amostra justifica-se pelo fato de o estudo ter como objetivo fazer um estudo exploratório da problemática.

Foram expostos às mulheres o tema de nosso estudo, sua relevância social, seus critérios científicos, a forma de divulgação dos resultados. $\mathrm{O}$ estudo foi submetido à apreciação do Comitê de Ética, sendo aprovado sob o protocolo 44002315.2.0000.5365.

Para a coleta de dados foi utilizado um questionário semiestruturado, composto por perguntas abertas e fechadas. Com o objetivo de verificar a forma adequada de formulação das perguntas, foram aplicados três pré-testes com mulheres que não participaram da pesquisa.

As perguntas fechadas consideraram as características sociodemográficas e reprodutivas das participantes, e as questóes emocionais e as relacionadas ao conhecimento sobre o câncer de mama. Quanto às características socioeconômicas: faixa etária (até 49 anos; de 50 a 59 anos; 60 anos ou mais); cor (branca; outras: preta/amarela/parda); escolaridade ( 9 ou mais anos; 5 a 8 anos; 0 a 4 anos); renda familiar; trabalha (sim; não); e estado civil (casada; solteira; viúva; uniāo estável). Em relação às características reprodutivas: idade da menarca (até 11 anos; 12 anos ou mais); aborto (não; sim); menopausa (sim; não); e história de câncer de mama (sim; não). Questóes relacionadas à saúde e às emoções: incapacidade física (não; sim; qual(is)); autoavaliaçẫo de saúde (ótima/boa; ruim/regular); apoio financeiro (sim; não; qual); apoio social (sim; não; qual), apoio familiar (sim; não; de quem). E características referentes ao conhecimento sobre o câncer de mama: realização do exame clínico das mamas e o autoexame e realização das mamografias de rastreamento.

A partir de duas perguntas abertas norteadoras: "quais os sentimentos e mudanças que ocorreram em sua vida após a mastectomia?"; e "como o grupo Rosa Mulher da Rede Feminina de Combate ao Câncer de Joinville contribui e o que ele representa na sua vida?", buscou-se identificar no relato das mulheres as mudanças que ocorreram em suas vidas e seus sentimentos após a descoberta do diagnóstico de câncer de mama.

O registro das repostas se deu por meio de gravação consentida pela pesquisada. Esse procedimento permitiu a reprodução das respostas com maior precisão, pois se pôde neutralizar os limites da memória e amenizar as distorçóes que eventualmente poderiam acontecer por ocasiáo de sua reproduçáo. A validação do conteúdo foi feita pela convidada após a transcrição do conteúdo.

As respostas das perguntas fechadas foram organizadas em programa Word, desenhado para o estudo. As variáveis pertinentes às características sociodemográficas e às reprodutivas, as concernentes à saúde e às questóes emocionais e as relacionadas ao conhecimento sobre o câncer de mama foram calculadas por meio de percentual.

Em relação às respostas das perguntas abertas, consideraram-se como respostas positivas os sentimentos de esperança, aceitaçáo, confiança, segurança, felicidade e de sentir-se bem e a autoimagem. Como negativos, os sentimentos de angústia, medo, decepção, abandono, revolta, choque, insegurança e de náo se sentir bem. Nessa etapa do estudo, os depoimentos foram transcritos em parte, e as mulheres foram identificadas por nomes de flores, como forma de garantir o anonimato.

$\mathrm{Na}$ análise dos achados foram consideradas as evidências científicas. Essa etapa inclui a comparação entre os resultados encontrados e as informaçóes presentes na literatura, visando identificar discordâncias ou similaridades com os achados, apesar das diferentes circunstâncias.

\section{Resultados e Discussão}

Este estudo constatou que as mulheres investigadas possuíam entre 35 a 70 anos, das quais $20 \%$ tinham entre 35 a 40 anos, $40 \%$ entre 41 a 50 anos, 30\% entre 51 a 60 anos e 10\% acima de 61 anos (Quadro 1), assemelhando-se, assim, a outras duas pesquisas que demonstraram o aumento do número de casos de câncer de mama para o perfil etário de 41 a $50 \operatorname{anos}^{9,10}$.

De acordo com o Ministério da Saúde ${ }^{1}$, a idade constitui o mais importante fator de risco para o câncer de mama, e o risco aumenta cerca de $70-80 \%$ o diagnóstico da neoplasia a partir dos 50 anos de idade. Além disso, há um aumento de mortalidade nessa faixa etária e nos casos de mastectomia, principalmente pelo fato de o diagnóstico ser realizado, na maioria das vezes, em estágios avançados da doença ${ }^{8}$.

Com respeito ao grau de escolaridade das mulheres estudadas, foram encontrados os percentuais de 50\% para o ensino fundamental incompleto e completo e $50 \%$ para o ensino médio incompleto e completo (Quadro 1). A comparaçáo da escolaridade das mulheres com câncer de mama encontrada em outra investigação mostra que a escolaridade das mulheres investigadas em Joinville é superior àquelas observadas em Fortaleza $-60,7 \%$ para o ensino fundamental incompleto e completo e 39,3\% para o ensino médio incompleto e completo - e em Uberaba - $61,11 \%$ para o ensino fundamental incompleto ${ }^{9,11}$. 
A renda mensal das participantes variou de 1 a 5 salários-mínimos: $70 \%$ recebem de 1 a 2 salários-mínimos e 30\% recebem de 3 a 5 salários-mínimos (Quadro 1). A confrontação dos percentuais de renda mensal de até 2 salários-mínimos encontrados em outros dois estudos mostra que a renda das mulheres investigadas neste estudo se aproxima das observadas no Centro Regional Integrado de Oncologia e da Santa Casa da Misericórdia de Fortaleza e em hospitais públicos no Distrito Federal, que identificaram percentuais de $74,4 \%$ e de $78 \%$, respectivamente ${ }^{11,12}$.

Em síntese, os dados deste estudo mostram um grupo composto, na maioria, por mulheres com baixa escolaridade e renda.

Para Tessaro ${ }^{13}$, o câncer de mama ocorre mais entre as mulheres com maior nível socioeconômico, provavelmente refletindo fatores ligados ao estilo de vida, em que a elevada escolaridade e a renda resultam em uma primeira gestação tardia, por exemplo. Entretanto, Di Pietro et al. ${ }^{14}$ referem que o risco de câncer de mama é maior entre as mulheres de baixa renda e de menor nível de escolaridade, o que, segundo os autores, pode estar associado a um estilo de vida mais estressante e à dificuldade de acesso aos serviços de saúde.

Silva et al. ${ }^{15}$ concluíram em seus estudos que as mulheres com baixo grau de instrução e dependentes do SUS têm maior probabilidade de descobrir os tumores da mama em estadiamentos tardios, pois o grau de instrução dificulta o entendimento de informações importantes sobre prevenção. As crenças e as percepçôes distorcidas da doença podem distanciar as mulheres que têm nível social mais baixo a procurar os serviços de saúde, o que contribui para diagnósticos tardios de neoplasias mamárias. É apontado, também, que as chances de uma mulher analfabeta ter um diagnóstico tardio e morrer de câncer de mama são 7,4 vezes maiores do que as mulheres que possuem o ensino superior. $\mathrm{O}$ impacto do câncer de mama é imenso para todas as mulheres, mas a literatura revela que, para aquelas provenientes de grupos populacionais socialmente desprivilegiados, as consequências podem ser ainda piores.

Hoffmann et al. ${ }^{16}$ descrevem em sua pesquisa que há várias evidências na literatura que confirmam que as mulheres com baixa renda familiar e com baixo nível de escolaridade têm as piores condiçóes socioeconômicas e, assim, a autoavaliação de saúde é negativa, devido à baixa procura e aderência a tratamentos nos serviços de saúde. Quanto ao estado civil, $80 \%$ das mulheres investigadas eram casadas e 20\% eram solteiras (Quadro 1).

No estudo, não houve casos de mulheres que demonstraram descrença. Houve, em todos os casos, uma crença presente de cura e afeto pela sua religião, seja ela católica, $80 \%$, batista, $10 \%$, ou evangélica, $10 \%$ (Quadro 1). Esses resultados estáo em consonância com o achado de outro estudo, mostrando que as mulheres com câncer de mama têm a dimensáo espiritual desenvolvida e que o aspecto religioso é muito presente ${ }^{8}$. Entretanto, Hoffmann et al. ${ }^{16}$ relatam que não há comprovaçóes científicas sobre a relação do câncer com a religiosidade, mas as crenças e o conforto que cada indivíduo demonstra durante os períodos de tratamento têm influência significativa na melhora da qualidade de vida.

Em relação à ocupação, no momento da entrevista, $30 \%$ das mulheres investigadas eram economicamente ativas, 20\% realizavam atividades no lar e 50\% declararam estar aposentadas, mas realizando serviços domésticos. Das aposentadas, $40 \%$ foram afastadas do trabalho por invalidez (Quadro 1). Um estudo realizado em centros especializados de tratamento oncológico das cidades de São José dos Campos e de Jacareí, ambas em São Paulo, constatou que $61,2 \%$ das investigadas tinham como ocupação os serviços domésticos e que $38,8 \%$ encontravam-se enquadradas em outro tipo de atividade ${ }^{17}$.

A cirurgia de retirada de parte da mama ou sua extirpação causam prejuízos para a elaboração de serviços domésticos, para a execuçáo dos afazeres laborais de rotina e para a sua profissão em si. Para Hoffmann et al. ${ }^{16}$, a mastectomia resulta no afastamento ou na aposentadoria de grande parte das mulheres afetadas pelo câncer de mama.

Quadro 1: Características socioeconômicas das mulheres mastectomizadas.

\begin{tabular}{|c|c|c|c|}
\hline \multicolumn{2}{|r|}{ Variáveis } & \multirow{2}{*}{$\begin{array}{c}\text { Quantidade } \\
2\end{array}$} & \multirow{2}{*}{$\begin{array}{l}\% \\
20\end{array}$} \\
\hline \multirow{4}{*}{$\begin{array}{l}\text { Idade no } \\
\text { diagnóstico }\end{array}$} & 35 a 40 anos & & \\
\hline & 41 a 50 anos & 4 & 40 \\
\hline & 51 a 60 anos & 3 & 30 \\
\hline & 61 a 70 anos & 1 & 10 \\
\hline \multirow{4}{*}{$\begin{array}{c}\text { Grau de } \\
\text { escolaridade }\end{array}$} & E.F. completo * & 2 & 20 \\
\hline & E.F. incompleto * & 3 & 30 \\
\hline & E.M. completo ${ }^{* *}$ & 3 & 30 \\
\hline & E.M. incompleto ${ }^{* *}$ & 2 & 20 \\
\hline \multirow{2}{*}{ Estado civil } & solteira & 2 & 20 \\
\hline & casada & 8 & 80 \\
\hline \multirow{2}{*}{ Renda familiar } & de 1 a 2 salários & 7 & 70 \\
\hline & de 3 a 5 salários & 3 & 30 \\
\hline \multirow{3}{*}{ Religião } & católica & 8 & 80 \\
\hline & batista & 1 & 10 \\
\hline & evangélica & 1 & 10 \\
\hline \multirow{3}{*}{ Ocupação } & aposentada $^{* * *}$ & 5 & 50 \\
\hline & do lar & 2 & 20 \\
\hline & economicamente ativa & 3 & 30 \\
\hline
\end{tabular}

Fonte: questionário semiestruturado

* Ensino Fundamental

** Ensino Médio

*** Duas das cinco mulheres aposentadas foram afastadas do trabalho por invalidez. 
A idade em que ocorreu a menarca (primeira menstruação) das mulheres investigadas variou de 11 a 13 anos (50\%) e de 14 a 17 anos (50\%). Constatou-se que $40 \%$ das entrevistadas entraram na menopausa antes dos 51 anos e que 60\% entraram após os 51 anos de idade (Quadro 2). Tanto a menarca precoce como a menopausa tardia foram observadas neste estudo. Um percentual importante das mulheres investigadas apresentou fator de risco para o câncer de mama em razáo de a menopausa ter acontecido após os 50 anos. É válido comentar que a mulher que entrou na menopausa somente após essa idade sofreu maior exposição a estrógenos endógenos, o que a fez ficar mais exposta a esse fator de risco'. Embora uma parte importante das mulheres não tenha apresentado menarca com idade igual ou inferior a 12 anos, estudos demonstram que a menarca precoce está intimamente relacionada a um aumento no risco relativo de ter câncer de mama devido ao fato de que, nessa situação, as mulheres - a exemplo da menopausa tardia - ficam expostas a estrógenos endógenos por maior período de tempo".

Houve relato de um caso de aborto entre as entrevistadas (Quadro 2). Em um estudo realizado no Rio de Janeiro, cerca de $40 \%$ das mulheres referiram história de aborto. Segundo esse estudo, um aborto é suficiente para colocar a mama em risco, sobretudo quando ocorre antes da primeira gestaçáo completa e em nulíparas, por expor o tecido mamário a uma maior concentração de estrógenos presentes na fase inicial da gestação ${ }^{8}$. Outro estudo aponta o aborto como fator de risco para o câncer de mama ${ }^{18}$. Entretanto, o estudo de Paiva et al. ${ }^{19}$ não encontrou significância estatística com relação ao câncer de mama e história de aborto.

Para Cihak e Glueck ${ }^{20}$, o fator de risco relacionado ao aborto pode estar associado ao câncer de mama, sendo este referente à indução da produção dos hormônios estradiol e progesterona, subsequente na transformação das células do tecido mamário que se dividem e se multiplicam, estimulando a produção do leite materno. Ao interromper uma gestação (aborto), o processo para no meio do caminho e muitas células ainda não diferenciadas em células de produção de leite têm grande potencial de transformarem-se em células cancerígenas.

Além dos hormônios, há evidências de que a genética também está associada ao câncer de mama, incluindo alteraçôes genéticas ou mutaçôes nos genes normais. Essas alteraçôes podem ser somáticas (adquiridas) ou da linhagem germinativa (herdadas). O histórico de câncer familiar acarreta o acompanhamento das mulheres de maneira preventiva. Recomenda-se que o autoexame e o exame clínico sejam feitos semestral ou anualmente e que a mamografia seja anual a partir dos 40 anos, independentemente da presença de nódulos palpáveis ${ }^{21}$.
Em relação a antecedentes familiares, $60 \%$ das mulheres deste estudo relataram ter caso de câncer de mama na família e 10\% mencionaram história de câncer de ovário (Quadro 2). De acordo com o Instituto Nacional de Câncer (INCA) ${ }^{22}$, a história familiar de câncer de mama aumenta em duas a três vezes o risco de desenvolver câncer de mama. Sclowitz et al. ${ }^{23}$ encontraram histórico familiar de câncer de mama mais frequente em casos do que em controles, relacionado principalmente a parente de primeiro grau, o que foi referido por $19 \%$ dos casos e por $8,1 \%$ de controles. O câncer hereditário de mama está relacionado à influência das mutações nos genes BRCA1, BRCA2 e principalmente no TP539. Apesar de mutaçôes nesses genes não serem frequentes, elas acontecem em torno de $20-30 \%$ dos casos estuda$\operatorname{dos}^{24}$. Já a história de câncer de ovário na família indica mutações nos genes BRCA1 e BRCA2. Portanto, o câncer de ovário também deve ser considerado como fator de risco para o câncer de mama .

Ao serem abordadas sobre o conhecimento e a prática do autoexame de mama (AEM), 80\% das mulheres investigadas neste estudo afirmaram que o conheciam e o praticavam (Quadro 2).

$\mathrm{Na}$ pesquisa com mulheres com câncer de mama, atendidas pelo Hospital de Clínicas da Universidade Federal do Triangulo Mineiro, 88,8\% conheciam e realizavam o $\mathrm{AEM}^{9}$. Apesar de o exame de mama náo ser o mais eficaz para a detecção precoce de câncer de mama, pois detecta a doença geralmente em estádio avançado, este tipo de exame é responsável por cerca de $80 \%$ das descobertas de cânceres de mama ${ }^{21}$.

Com relação à periodicidade das mamografias, $90 \%$ das mulheres em estudo relataram rastreamentos anuais (Quadro 2). De acordo com o Ministério da Saúde ${ }^{21}$, os meios mais eficazes para a detecção precoce de câncer de mama são o ECM e a mamografia.

Semelhante a outro estudo, nossos dados revelaram que as mulheres têm procurado o exame mamográfico em razão dos altos percentuais de mamografias realizadas, principalmente quando os percentuais de cobertura chegam a $90 \%{ }^{25}$. Com base no relatório do sistema de informação do câncer de mama (SISMAMA), o número de mamografias no Brasil triplicou em 2010 em relação a $2009^{26}$. Os altos percentuais aqui encontrados, no que tange ao AEM, ao exame mamográfico e à procura por consultas ginecológicas (80\%), podem estar demonstrando o cuidado das mulheres com sua própria saúde.

Observa-se neste estudo que $60 \%$ das mulheres tinham menos de 50 anos quando realizaram a amputação da mama (Quadro 2). A idade, de acordo com alguns autores, é um fator importante na aceitação da mastectomia em razáo de as mulheres mais jovens apresentarem maior prejuízo de sua imagem corporal do que mulheres acima de 50 anos $^{27}$. 
Quadro 2: Características reprodutivas das mulheres mastectomizadas.

\begin{tabular}{|c|c|c|c|}
\hline \multicolumn{2}{|c|}{ Variáveis } & Quantidade & $\%$ \\
\hline \multirow{2}{*}{ Menarca } & 11 a 13 anos & 5 & 50 \\
\hline & 14 a 17 anos & 5 & 50 \\
\hline \multirow{4}{*}{ Idade da menopausa } & 40 a 50 anos & 3 & 30 \\
\hline & $<51$ anos & 4 & 40 \\
\hline & 51 a 60 anos & 6 & 60 \\
\hline & 61 a 80 anos & 0 & 0 \\
\hline \multirow{2}{*}{ Aborto } & $\operatorname{sim}$ & 1 & 10 \\
\hline & não & 9 & 90 \\
\hline \multirow{2}{*}{$\begin{array}{l}\text { Histórico familiar de } \\
\text { câncer de mama }\end{array}$} & $\operatorname{sim}$ & 6 & 60 \\
\hline & não & 4 & 40 \\
\hline \multirow{2}{*}{$\begin{array}{l}\text { Histórico familiar de } \\
\text { câncer de ovário }\end{array}$} & $\operatorname{sim}$ & 1 & 10 \\
\hline & não & 9 & 90 \\
\hline \multirow{2}{*}{ Autoexame } & $\operatorname{sim}$ & 8 & 80 \\
\hline & não & 2 & 20 \\
\hline \multirow{2}{*}{$\begin{array}{l}\text { Frequência de consulta } \\
\text { ginecológica }\end{array}$} & $\operatorname{sim}$ & 8 & 80 \\
\hline & não & 2 & 20 \\
\hline \multirow{2}{*}{ Mamografias periódicas } & $\operatorname{sim}$ & 9 & 90 \\
\hline & não & 1 & 10 \\
\hline \multirow{4}{*}{ Idade da mastectomia } & 35 a 40 anos & 2 & 20 \\
\hline & 41 a 50 anos & 4 & 40 \\
\hline & 51 a 60 anos & 3 & 30 \\
\hline & 61 a 70 anos & 1 & 10 \\
\hline
\end{tabular}

Fonte: questionário semiestruturado.

Quando perguntadas sobre a questão de saúde, 70\% das mulheres deste estudo citaram incapacidade física; $70 \%$, doenças crônicas; e $50 \%$, um pouco de tensão psicológica. Mesmo assim, $60 \%$ das pesquisadas declararam ter saúde boa; $10 \%$, péssima; e $30 \%$, regular (Quadro 3). O estudo de Pinto e Gióia-Martins ${ }^{28}$ encontrou percentuais de $60 \%$ para as mulheres com câncer de mama que relataram dificuldades físicas, principalmente para carregar objetos pesados, realizar atividades diárias e fazer caminhadas. Aproximadamente $72 \%$ das mulheres investigadas pelos autores referiram níveis de tensão emocional. Desse percentual, $80 \%$ afirmaram sentir nervosismo; $60 \%$, muita preocupação; e $80 \%$, irritação fácil.

Em relação à autoavaliação das mulheres sobre suas condiçóes de saúde, este estudo se aproxima da pesquisa de Höfelmann e Anjos. ${ }^{29}$. Os autores, ao investigarem 170 mulheres com câncer de mama atendidas no setor público de Joinville, constataram que $61 \%$ delas referiram ter boa saúde e 29,4\% afirmaram ter saúde regular. Entretanto, essa mesma investigaçáo distancia-se deste estudo no que tange à presença de doenças crônicas entre as entrevistadas, em razão de terem encontrado somente $47 \%$ de mulheres que mencionaram a presença de outra doença crônica associada.

As alteraçôes físicas estão diretamente associadas às doenças crônicas e psicológicas, pois a mulher após a mastectomia se sente depressiva e com medo, e sua autoestima diminui, o que origina fortes sofrimentos psicológicos, que desencadeiam reaçóes no corpo, como doenças crônicas e outras ${ }^{30}$.

Em relação ao apoio financeiro, $20 \%$ das mulheres investigadas neste estudo referiram receber a ajuda e $80 \%$ náo (Quadro 3). O estudo de Tavares e Trad ${ }^{31}$ mostra que o adoecimento por câncer gera, por vezes, ansiedade devido ao afastamento da paciente de suas atividades produtivas e à necessidade de constantes deslocamentos das pacientes e seus familiares para tratamento hospitalar. Dizem os autores que o afastamento das atividades produtivas e domésticas repercutem não só financeiramente, mas também emocionalmente nas pacientes.

Nesse caso, é necessário salientar que a disponibilidade de certos recursos materiais pode ter papel crucial na continuidade do tratamento. Assim, conhecer as necessidades de apoio apontadas por doentes oncológicos favorece o planejamento de açóes adequadas às necessidades de cada mulher.

No que diz respeito ao apoio social, $10 \%$ das entrevistadas citaram receber algum tipo de apoio social, entretanto $90 \%$ negaram receber qualquer apoio. Aqui identificamos certa contradição, uma vez que $100 \%$ das mulheres investigadas confirmaram a participação no grupo de apoio Rosa Mulher (Quadro 3). O que nos parece é que elas não identificam as relações de troca, os vínculos e laços que criam ao participarem do grupo como sendo uma espécie de apoio social.

Todas as mulheres pesquisadas responderam que têm apoio familiar (Quadro 3). Wanderbroocke ${ }^{32}$ confirma a família do doente com câncer como a principal fonte de apoio para o paciente. Para ele, o binômio paciente-cuidador é uma unidade de atenção por ser um "invisível sistema de cuidado da saúde", no qual o câncer deve ser tratado como problema e questáo familiar.

Após a mastectomia, a mulher se sente fragilizada e esse impacto causa danos extensivos à sua vida social e familiar; portanto, todo apoio que lhe for disponibilizado é de grande relevância e fundamental para tomadas de decisão, transformaçóes, conceitos e enfrentamento da situaçãa ${ }^{30}$.

Em nosso estudo, houve aceitação da mastectomia por uma participante e as demais relataram medo, insegurança e tristeza (Quadro 3). Ou seja, nota-se que $90 \%$ das mulheres desta investigação sentem-se desoladas mediante a mutilação a que foram submetidas. A pesquisa realizada por Regis e Simôes ${ }^{33}$ em relação a mulheres mastectomizadas observa sentimentos de 
tristeza e de depressão por parte das mulheres. As consequências da mastectomia na mulher refletem na tristeza relacionada à mutilação de uma parte do corpo, a depressão, muitas vezes associada à sua própria imagem construída em pensamentos, e sua aceitação como uma chance de cura e uma necessidade para se evitar a morte.

No que se refere à participação das mulheres nos grupos de apoio, constatamos que todas fazem parte dessa atividade e elas referem que isso as ajudou a aceitar melhor a doença e o tratamento (Quadro 3). Em consequência, podemos considerar que os grupos de apoio constituem um dos formatos mais frequentemente utilizados pelas mulheres acometidas por câncer de mama. A literatura científica especializada, sobretudo a internacional, tem demonstrado, na última década e por uma série de estudos que se propõem a descrever ou avaliar o funcionamento de grupos de apoio a mulheres acometidas por câncer de mama, os benefícios importantes desse tipo de intervenção, sobretudo em termos psicológicos e sociais ${ }^{34}$.

Quadro 3: Implicações do câncer de mama para a vida emocional, física e social das mulheres mastectomizadas.

\begin{tabular}{|c|c|c|c|}
\hline \multicolumn{2}{|c|}{ Variáveis } & Quantidade & $\%$ \\
\hline \multirow{2}{*}{$\begin{array}{l}\text { Incapacidade } \\
\text { física }\end{array}$} & $\operatorname{sim}$ & 7 & 70 \\
\hline & não & 3 & 30 \\
\hline \multirow{2}{*}{$\begin{array}{l}\text { Doença } \\
\text { crônica }\end{array}$} & $\operatorname{sim}$ & 7 & 70 \\
\hline & não & 3 & 30 \\
\hline \multirow{3}{*}{$\begin{array}{l}\text { Tensão } \\
\text { psicológica }\end{array}$} & um pouco & 5 & 50 \\
\hline & não & 4 & 40 \\
\hline & bastante & 1 & 10 \\
\hline \multirow{3}{*}{$\begin{array}{l}\text { Autoavaliação } \\
\text { da saúde }\end{array}$} & boa & 6 & 60 \\
\hline & péssima & 1 & 10 \\
\hline & regular & 3 & 30 \\
\hline \multirow{2}{*}{$\begin{array}{l}\text { Apoio } \\
\text { financeiro }\end{array}$} & $\operatorname{sim}$ & 2 & 20 \\
\hline & não & 8 & 80 \\
\hline \multirow{2}{*}{ Apoio social } & $\operatorname{sim}$ & 1 & 10 \\
\hline & não & 9 & 90 \\
\hline \multirow{2}{*}{ Apoio familiar } & $\operatorname{sim}$ & 10 & 10 \\
\hline & não & 0 & 0 \\
\hline \multirow{3}{*}{$\begin{array}{l}\text { Sentimento } \\
\text { após a } \\
\text { mastectomia }\end{array}$} & aceitação & 1 & 10 \\
\hline & medo e insegurança & 3 & 30 \\
\hline & tristeza & 6 & 60 \\
\hline \multirow{2}{*}{$\begin{array}{l}\text { Participaçáo } \\
\text { no grupo de } \\
\text { apoio }\end{array}$} & melhor aceitação & 10 & 100 \\
\hline & não houve diferença & - & - \\
\hline
\end{tabular}

Fonte: Questionário semiestruturado.

A análise de algumas perguntas abertas possibilitou compreender como a mulher vivencia as experiências do diagnóstico, do tratamento do câncer de mama e das mudanças em sua vida decorrentes desse processo. A partir dos dois questionamentos - "Quais os sentimentos e mudanças que ocorreram em sua vida após a mastectomia?" e "Como o grupo Rosa Mulher da Rede Feminina de Combate ao Câncer de Joinville contribui e o que ele representa na sua vida?" -, abriu-se um leque de sentimentos que foram manifestados pelas entrevistadas.

Puderam ser percebidos, na fala das entrevistadas, principalmente sentimentos de desespero, medo, culpa e tristeza, que foram demonstrados por consternaçáo e choro. Em seus relatos, as entrevistadas disseram o seguinte sobre a descoberta do câncer de mama: "Quando descobri e caiu minha ficha, eu me perguntei: Por que eu? Pensei vai cair meu cabelo, pensei em me apegar com Deus, as pessoas dão palavras amigas, mas não como a misericórdia de Deus!" (Lírio).

E ainda:

Um caminho bem longo, aí eu sai do Abdon Batista até eu chegar no Dona Helena, foi parece uma viagem até o Rio Grande não chegava nunca, né? Aí eu cheguei e no hospital e falei com a minha chefe que náo ia voltar a trabalhar que eu teria que tirar a mama, ai foi que ela me falou pra mim: "Mais uma vitima", aí meu Deus, desabo né? Chorei daí, meu pensei daí que sou a próxima vítima, que vou morrer, né? (Três-marias).

A narrativa dessas mulheres é suficiente para ilustrar aquilo que chamamos de tristeza e desalento. A sensação de estar com câncer era sinônimo de morte para TrêsMarias. Fernandes e Mamede ${ }^{35}$ comentam que o medo é frequente entre as mulheres com câncer de mama por estigmatizarem a doença como letal, transmitindo, dessa forma, a vivência de uma cultura na qual ter câncer é sinônimo de morte.

Para Lírio, a fé em Deus foi a alternativa encontrada para o enfrentamento da doença. Essa manifestação de religiosidade sugere que, para Lírio, sua cura poderia ser alcançada pela compaixão de Deus. A presença da fé em Deus e a espiritualidade têm sido descritas por autores que investigam a vida de pacientes oncológicas. Para eles, a religiosidade faz que as mulheres adotem uma postura aparentemente mais forte, como forma de ajudar a enfrentar o tratamento ${ }^{36}$.

A mastectomia é um procedimento cirúrgico agressivo, que traz consequências traumáticas, refletindo na vida e na saúde da mulher. Desperta sentimentos de negação, dificultando a aceitação de sua imagem, o que pode fazer surgir sequelas psicológicas ainda mais complicadas do que a deformidade da extirpação da mama. A mulher fica frágil emocionalmente, deparando com dificuldades a serem superadas ${ }^{37}$. 
Pelos depoimentos feitos durante a entrevista, pôde-se constatar que todas as mulheres enxergavam a retirada da mama como uma perda da feminilidade e da estética. De acordo com elas: "Demorei muito a me olhar no espelho e quando vi disse: 'Que judiação', depois comecei a aceitar melhor, mas quando coloco uma roupa sinto falta da minha mama. A mama é muito importante para a imagem da mulher" (Lírio).

Depois da cirurgia, me vi ridícula sem a mama! Feia! Não tinha coragem de me olhar no espelho! Levei seis meses para me olhar no espelho, não tinha coragem de me ver. A mama representava tudo, a minha feminilidade. A gente sem a mama as pessoas já vem de frente e já olham, nunca fiquei sem minha prótese, nem pra dormir (Gérbera).

Os padróes impostos pela sociedade exigem um corpo perfeito e formas admiráveis. A mulher, quando mutilada, vê sua intimidade violada, sentindo-se inferior esteticamente e "imperfeita"; compara-se às demais com a concepção de um corpo alterado e diferente, principalmente ao se olhar no espelho e ver a mutilação abrupta. As modificaçóes da imagem corporal acarretam sentimentos, emoçóes, ansiedade, tristeza, medo e vergonha em se despir, pois o desfiguramento muda muito as percepçóes na vivência da mulher mastectomizada e na busca de uma nova organizaçáo de sua vida para não perder o controle da situaçáo ${ }^{38}$. De acordo com as mulheres: "A mama representava muito pra mim, não poderia me imaginar sem a mama, é uma parte do corpo da gente. Depois que tira, a gente fica deformada! Se olha no espelho e fica reta" (Cravo).

E mais:

Quando me vi sem a mama me senti esquisita [...] Faço hidroginástica e tenho vergonha de despir e vestir na frente dos outros, me visto no banheiro para que ninguém me veja. Parece que a gente não se sente inteira, não se doa inteira, parece que está faltando alguma coisa (Margarida).

A baixa autoestima depois do pós-operatório de mastectomia configura um dos maiores problemas apresentados pela mulher, pois ela relata a sensação de impotência diante da mutilação física e o medo de não ser mais vista como perfeita, diminuindo assim a capacidade de voltar à sua vida normal em todos os segmentos biopsicossociais ${ }^{5}$. Para Toriy et al. ${ }^{38}$, a mulher se preocupa e tem medo dos preconceitos da sociedade sobre o câncer; tem medo de sua atual imagem mutilada ser associada a uma patologia contagiosa, o que gera ainda mais sofrimento.

Em todas as etapas do tratamento, a família representa o alicerce, não se restringindo ao aspecto psicológico, mas à valorização da mulher em fase de tratamento da doença como componente importante no núcleo familiar ${ }^{39}$.

Foi possível perceber, no relato das mulheres, a importância dada ao suporte dos familiares, quanto ao enfrentamento do problema por parte deles e a necessidade do acolhimento - "Eu chorava muito e, ao mesmo tempo, eu levantava a cabeça e minha família estava sempre ali me ajudando; sempre tive apoio da minha família" (Girassol), e "Minha família me apoiou, ficaram preocupados, não tentaram me derrubar, me levantaram e não sentiram pena de mim" (Cravo).

Entende-se que a importância do apoio familiar para as mulheres mastectomizadas consiste no sentimento de luta e no encontro de forças para a realização dos tratamentos agressivos à saúde. Esse apoio é refletido na recuperaçáo da mente, do corpo e, sobretudo, do lado psicológico para o término do tratamento.

Silva e Santos. ${ }^{39}$ afirmam que "é possível ressaltar que a uniáo e a proximidade afetiva entre os membros da família favorecem um ambiente harmonioso, assim como ajuda física, emocional e cuidado às mulheres". No entanto, também existem casos em que a família é afetada de tal forma, que não sabe como reagir diante da pessoa enferma; nesse sentido, configura-se que as orientaçóes dos profissionais da saúde podem proporcionar à família o suporte adequado durante o tratamento da neoplasia.

Quanto à religião, a mulher busca conforto espiritual com o intuito de buscar os sentimentos de fé, esperança e estar mais perto de Deus. Para elas, é o único alívio dos seus sofrimentos em busca da cura. A fé ajuda a renovar e a reorganizar suas vidas, proporciona uma visão positiva da sua situação atual e desconstrói sentimentos negativos de morte. A religião traz uma nova concepção para lidar com a doença e com a mutilação, assegurando maior estabilidade emocional, proteção e conforto por meio do apoio espiritual 5 .

A maioria das mulheres que participou da pesquisa referenciou a crença em Deus para buscar equilíbrio emocional e esperança: "Daí, comecei a ver as missas na televisão e pedir a Deus. Falei: 'Senhor, já que tenho essa doença, te peço que me dê coragem pra enfrentar. Também sou tua filha e quero ser curada!'”(Gérbera), e "Cada um tem a sua parte e a minha era aceitar e crer que Deus estaria comigo. E eu confiei demais no médico e pensei que Deus vai me tirar dessa" (Margarida).

$\mathrm{O}$ bem-estar espiritual dos indivíduos portadores de doenças graves foi identificado, em vários estudos, como um fator de proteção, estando relacionado a atitudes positivas de combate à enfermidade ${ }^{40}$.

Para Caetano, Gradim e Santos ${ }^{41}$, a religiosidade é uma das alternativas que as mulheres mastectomizadas buscam para enfrentar uma doença chamada câncer de mama. Após o diagnóstico, a maioria das mulheres 
descreve a espiritualidade como buscar sua cura em Deus. A religião traz uma força de fé e esperança. Apesar de novas tecnologias e de novos tratamentos, a busca divina ainda é cultural em pacientes oncológicos e traz a sensação de bem-estar e uma postura mais forte, uma vez que eles acreditam que, com fé, tudo dará certo.

Nos relatos a seguir, evidenciamos a manifestação das mulheres sobre a relação marital: "Tenho vergonha do meu marido, náo gosto de me vestir perto do meu marido. Apesar de meu marido dizer que não mudou nada na relação, eu percebo que mudou sim, náo muito pra ele, mas pra mim" (Margarida), e "Atrapalhou, porque eu fiquei complexada. Então, porque, se a gente vai ter relação, eu tenho que estar de blusa, sutiã, porque não quero que veja ali, não pode tocar mais nada" (Hortência).

Fica explícito, na fala de Hortência, que a mastectomia interferiu de maneira importante na qualidade do vínculo com seu parceiro.

No entanto, a ajuda do cônjuge torna-se um elo de confiança e fortalece a relaçáo entre ambas as partes. Entre os fatores que podem facilitar a retomada da vida sexual pós-mastectomia, destaca-se a postura compreensiva e acolhedora do companheiro que é manifestada nos relatos a seguir: "Minha relaçáo com meu marido continua a mesma coisa. Ele disse que o mais importante é minha cura. Ele me ajuda e me dá muita força e nada mudou na minha relaçáo sexual. Meu marido é muito importante e me ajuda muito" (Lírio). Ou ainda: "Então, eu tinha três filhos pequenos; então, eu tinha que lutar. Nunca chorei na frente de médico, nunca chorei na frente de... Só na frente do meu marido. Nunca na frente de filho. De mãe, então, nem pensar" (Copo-de-leite).

Percebemos, pelas manifestações das mulheres entrevistadas, que a maioria delas possuía relacionamentos conjugais construídos com base na aceitação do outro como ele é. Entretanto, uma das mulheres parece se afastar do companheiro ao não permitir um maior contato físico.

Silva e Santos ${ }^{39}$, em sua pesquisa, mencionam a relevância do casamento, pois mulheres casadas temem ser desprezadas pelo companheiro, o que interfere em sua sexualidade.

Duarte e Andrade ${ }^{42}$ concluíram que não existe um padrão de reação das mulheres que sofreram amputação da mama diante do parceiro. Algumas se afastam e outras se aproximam mais dos companheiros. É importante ressaltar que muitas mulheres temem a náo aceitação, pelo parceiro, de sua nova condição, o que para as autoras, deve-se ao fato de essas mulheres associarem sexualidade à genitalidade, o que as leva a pensar que a ausência das mamas tende a provocar necessariamente um distanciamento do companheiro.

A reconstrução da mama pode influenciar muito a qualidade de vida da mulher mastectomizada, pois sua autoimagem é mudada de forma brusca e sua visão é de um corpo mutilado após a cirurgia, tendo como consequências a mudança de seus sentimentos de vergonha, medo e insegurança e a readaptação na sociedade ${ }^{37}$. Para Moura $^{5}$, a cirurgia plástica de reconstrução da mama é uma das opçóes que algumas mulheres encontram para amenizar, após a retirada da mama, os sentimentos de negatividade perante a sociedade, pois sentem-se inferiorizadas em relaçáo a outras mulheres. Porém, esse procedimento deve ser avaliado por um médico especializado, para não gerar expectativas de uma mama perfeita, ou seja, igual à anterior que foi retirada. Muitas vezes, a mulher é influenciada por sentimentos de rejeição, comuns a essa situação, surgidos repentinamente em sua vida por se ver sem mama e por ter sua sexualidade afetada. Decide fazer uma cirurgia de reconstrução sem entender o que realmente pode acontecer, gerando sentimentos de frustração, desânimo e depressão.

No discurso de uma das participantes, percebe-se o incômodo vivenciado pela possibilidade da recidiva da doença, baseado no pensamento de que o câncer é incurável e que, se mexer no local da remoção da mama, pode voltar a qualquer momento: "Não penso em fazer reconstrução da mama, porque meu câncer voltou e tenho medo. Melhor não mexer no que está quieto, deixa assim! Às vezes, tenho vontade, mas fico com medo" (Lírio).

Estudos mostram que o receio da recidiva é comum entre mulheres mastectomizadas e que está intrinsecamente relacionado à incerteza quanto à consistência da melhora e da cura $^{39}$.

Contudo, com a reconstrução da mama, a qualidade de vida das mulheres relacionada ao conceito de sua autoimagem aumenta muito, melhora o relacionamento sexual e o processo de reabilitação, tornando-o menos traumático, e diminuem os acompanhamentos psicológicos intensificados por causa da depressão. A maioria das mulheres que opta por fazer o referido procedimento estético sente-se imediatamente mais feliz com os resultados e menos deprimida ao se olhar no espelho. Mulheres que optam pela cirurgia tardia tendem a um sofrimento psíquico maior, alicerçado na baixa autoestima, em atitudes negativas e na insatisfação com sua aparência ${ }^{30}$.

Nota-se, na fala de Gérbera, os efeitos positivos da mastectomia na imagem corporal. A fala traduz a importância que essa mulher atribui à sua aparência física: "Depois de dois anos, fiz a reconstrução da mama e, meu Deus, foi uma alegria. Quando acordei da anestesia, a enfermeira falou - 'coloca sua mãozinha aqui'. Ai, não tive coragem, mas depois coloquei. Disse 'Obrigada, meu Deus" (Gérbera).

Os resultados da maioria dos estudos analisados apontam que houve melhora na qualidade de vida das mulheres que realizaram a reconstrução mamária em comparação com as que não realizaram a cirurgia ${ }^{5}$. Os 
dados demonstram a relevância de se oferecer à mulher a possibilidade de reconstruir sua mama.

Quando perguntadas sobre o que o grupo Rosa Mulher representava em suas vidas, as respostas seguiram o seguinte pensamento: "O que posso fazer e o que náo posso fazer aprendi aqui. Melhorou minha qualidade de vida. As palestras me ajudam muito. O contato com as outras mulheres do grupo, o trocar ideias é muito bom" (Margarida).

Conforme outro relato:

Gosto do grupo. Tem palestras importantes com médicos, nutricionistas, fisioterapeuta, psicólogas e isso é muito importante. Todas as informaçôes repassadas por médicos e em programas de televisão, gosto de ouvir. Essas informaçóes acrescentaram e me ajudaram a conhecer mais a doença $e$ melhorou minha qualidade de vida, minha alimentação. Cuido mais do que eu como (Gérbera).

O pensamento dessas mulheres mostra que os grupos de apoio social contribuem para a melhora da qualidade de vida, uma vez que proporcionam encontros, palestras, atividades de recreação e, acima de tudo, orientaçóes durante e após o tratamento.

Além disso, segundo Copo-de-leite:

Ah! Muita insegurança, principalmente para ir pra praia no começo. Foi por isso que eu vim à Rede, pra saber como uma pessoa mastectomizada vai pra praia, porque meu filho não aceitava que eu fosse pra praia com ele. Então, a primeira coisa foi... Como ir pra praia sem mama (Copo de Leite).

Diversos autores referem que as práticas grupais são especialmente proveitosas, pois a universalidade da queixa facilita a expressáo de sentimentos e a troca de experiências relacionadas à doença e ao tratamento, o que tende a diminuir o nível de ansiedade das participantes e potencializar a ocorrência de processos de mudança. Ademais, sentimentos de isolamento e de solidão podem ser trabalhados em grupo, o que auxilia a diminuir o estigma associado ao câncer de mama ${ }^{34}$.

Todas as falas das mulheres convidadas para a pesquisa afirmaram que o grupo representa, no seu cotidiano, uma forma de cuidado e de compartilhamento das superaçóes e das experiências, um acolhimento para aquelas que descobrem a doença recentemente e uma fonte de ajuda e de força para continuarem a batalha contra a doença.

\section{Conclusões}

Os achados deste estudo encontram-se em consonância com os dados da literatura, apontando os sentimentos vivenciados pelas mulheres com câncer como uma sensação psíquica que explica as disparidades no enfretamento da doença de acordo com a realidade de cada mulher.

Este estudo possibilitou o conhecimento acerca das características e dos sentimentos das mulheres portadoras de câncer e mastectomizadas que frequentam o grupo Rosa Mulher. Os sentimentos percebidos foram tristeza, angústia, depressão, revolta pela mutilação, medo da morte, vergonha, fé e esperança.

Foi possível identificar, a partir desta investigação, quais os suportes essenciais para essas mulheres. Para elas, a própria família e o grupo de apoio trazem benefícios para diminuir os níveis de desesperança, preocupação e medo.

Outro aspecto constatado neste estudo é que a confirmação do diagnóstico de câncer trouxe profundas mudanças na vida de cada uma das mulheres entrevistadas. As novas formas de enfrentamento da vida expressaram-se nas expectativas voltadas para cura e na necessidade de apego religioso.

Consideramos que a mastectomia, por ser traumática, pode ser mais bem superada se a mulher, nesse período de adaptaçáo e de nova realidade, tiver apoio familiar, de amigos, espiritual, médico e psicológico, atrelado a um grupo de apoio como peça fundamental para melhorar a expectativa de vida, sendo valorizada em sua singularidade com uma visão holística e humanizada.

Por fim, por se tratar de um problema que tem magnitude importante, seria notável e desejável que fossem realizados estudos que aprofundassem a pesquisa de outros mecanismos e processos que pudessem auxiliar as mulheres com câncer de mama a enfrentar e mediar as de mudanças em suas vidas devido à mastectomia.

\section{Referências}

1. Brasil. Ministério da Saúde. Secretaria de Atenção à Saúde. Departamento de Atenção Básica. Controle dos cânceres do colo do útero e da mama. $2^{a}$ ed. Brasília: Ministério da Saúde; 2013.

2. Trufelli DC, Miranda VC, Santos MBB, Fraile NMP, Pecoroni PG, Gonzaga SFR, et al. Análise do atraso no diagnóstico e tratamento do câncer de mama em um hospital público. Rev Assoc Med Bras [Internet]. 2008 fev [acesso em 2015 nov 18];54(1):72-6. Disponível em: http://dx.doi. org/10.1590/S0104-42302008000100024

3. Instituto Nacional de Câncer José Alencar Gomes da Silva. Coordenação de Prevenção e Vigilância. Estimativa 2014: incidência de câncer no Brasil. Rio de Janeiro: Inca; 2014.

4. National Breast and Ovarian Cancer Centre. Lymphedema: prevalence, risk factors and management. [Internet]. 2009. 
[acesso em 2015 nov 18]. Disponível em: http://canceraustralia.nbocc.org.au/view-document-details/lym-lymphoedema-prevalence-risk-factors-and-management-a-review-of-research

5. Moura FMJSP, Silva MG, Oliveira SC, Moura LJSP. Os sentimentos das mulheres pós-mastectomizadas. Esc Anna Nery [Internet]. 2010 jul-set [acesso em 2015 nov 18];14(3):477-84. Disponível em: http://dx.doi. org/10.1590/S1414-81452010000300007

6. Rosa LM, Radünz V. Significado do câncer de mama na percepção da mulher: do sintoma ao tratamento. Rev Enferm UERJ [Internet]. 2012 out-dez [acesso em 2015 nov 18];20(4):445-50. Disponível em: http://www.e-publicacoes. uerj.br/index.php/enfermagemuerj/article/view/4673/3452

7. Geraldini MCCS, Moura L. Sentimentos relatados por mulheres mastectomizadas: uma revisão sistematizada. Revista Uningá [Internet]. 2013 [acesso em 2015 nov 11];38:17588. Disponível em: http://www.mastereditora.com.br/ periodico/20140131_112004.pdf

8. Pinho VFS, Coutinho ESF. Variáveis associadas ao câncer de mama em usuárias de unidades básicas de saúde. Cad Saúde Pública [Internet]. 2007 maio [acesso em 2015 nov 08];23(5):1061-9. Disponível em: http://dx.doi. org/10.1590/S0102-311X2007000500008

9. Silva PA, Riul SS. Câncer de mama: fatores de risco e detecção precoce. Rev Bras Enferm [Internet]. 2011 nov-dez [acesso em 2015 nov 01];64(6):1016-21. Disponível em: http://dx.doi.org/10.1590/S0034-71672011000600005

10. Bairros FS, Meneghel SN, Dias-da-Costa JS, Bassani DG, Menezes AMB, Gigante D P, et al. Racial inequalities in access to women's health care in southern Brazil. Cad Saúde Pública [Internet]. 2011 dez [acesso em 2015 nov 18];27(12):2364-72. Disponível em: http://dx.doi. org/10.1590/S0102-311X2011001200008

11. Lôbo SA, Fernandes AFC, Almeida PC, Carvalho CML, Sawada NO. Qualidade de vida em mulheres com neoplasias de mama em quimioterapia. Acta Paul Enferm [Internet]. 2014; [acesso em 2015 out 18];27(6):554-9. Disponível em: http://www.scielo.br/pdf/ape/v27n6/19820194-ape-027-006-0554.pdf

12. Barros AF, Uemura G, Macedo JLS. Tempo para acesso ao tratamento do câncer de mama no Distrito Federal, Brasil Central. Rev Bras Ginecol Obstet [Internet]. 2013 [acesso em 2015 out 12];35(10):458-63. Disponível em: http://dx. doi.org/10.1590/S0100-72032013001000006

13. Tessaro S. Epidemiologia do câncer de mama. In: Boff RA, organizador. Mastologia aplicada: abordagem multidisciplinar. Caxias do Sul: Educs; 2001. p. 15-28.

14. Di Pietro PF, Medeiros NI, Vieira FG, Fausto MA, BellóKlein A. Breast cancer in southern Brazil: association with past dietary intake. Nutr Hosp [Internet]. 2007 set-out [acesso em 2015 nov 10];22(5):565-72. Disponível em: http://www.ncbi.nlm.nih.gov/pubmed/17970540

15. Silva PF, Amorim MHC, Zandonade E, Viana KCG. Associação entre variáveis sociodemográficas e estadiamento clínico avançado das neoplasias da mama em hospital de referência no estado do Espírito Santo. Rev Bras Cancerol [Internet]. 2013 [acesso em 2015 out 10];59(3):361-7. Disponível em: http://pesquisa.bvsalud.org/sms/resource/ pt/lil-724472

16. Hoffmann FS, Müller MC, Rubin R. A mulher com câncer de mama: apoio social e espiritualidade. Mudanças [Internet]. 2006 jul-dez [acesso em 2015 out 15];14(2):14350. Disponível em: https:/www.metodista.br/revistas/revistas-ims/index.php/MUD/article/view/645/645

17. Mendes IS, Freitas STT, Souza GC, Reis MCR, Souza DQ, Lima SPF, et al. Correlação da dor e qualidade de vida de mulheres pós-tratamento cirúrgico de câncer de mama. Mundo Saúde [Internet]. 2014 [acesso em 2015 out 12];38(2):189-96. Disponível em: http://www.saocamilo-sp.br/pdf/mundo_saude/155562/A07.pdf

18. Gomes AL, Guimarães MD, Gomes CC, Chaves IG, Gobbi H, Camargos AF. A case-control study of risk factors for breast cancer in Brazil, 1978-1987. Int J Epidemiol [Internet]. 1995 abr [acesso em 2015 out 07];24(2):2929. Disponível em: http://www.ncbi.nlm.nih.gov/ pubmed/7635588

19. Paiva CE, Ribeiro BS, Godinho AA, Meirelles RSP, Silva EVG, Marques GD, et al. Fatores de risco para câncer de mama em Juiz de Fora (MG): um estudo caso-controle. Rev Bras Cancerol [Internet]. 2002 [acesso em 2015 out 17];48(2):231-7. Disponível em: http://www.inca.gov.br/ rbc/n_48/v02/pdf/artigo3.pdf

20. Cihak R, Glueck M. The link between breast cancer and abortion. USA: Discovery Institute. [Internet]. 2005 [acesso em 2016 jul 6]. Disponível em: http://www.discovery.org/a/3018

21. Brasil. Ministério da Saúde. Secretaria de Assistência à Saúde. Instituto Nacional de Câncer. Coordenaçáo de Prevenção e Vigilância (Conprev). Falando sobre câncer de mama. Rio de Janeiro: MS/Inca, 2002.

22. Instituto Nacional de Câncer José Alencar Gomes da Silva. Coordenação Geral de Açôes Estratégicas. Coordenação de Prevenção e Vigilância. Estimativa 2012: incidência de câncer no Brasil. Rio de Janeiro: Inca, 2011.

23. Sclowitz ML, Menezes AMB, Gigante DP, Tessaro S. Condutas na prevenção secundária do câncer de mama e fatores associados. Rev Saúde Pública [Internet]. 2005 [acesso em 2015 nov 18];39(3):340-9. Disponível em: http://dx. doi.org/10.1590/S0034-89102005000300003

24. Pharoah PDP, Day NE, Caldas C. Somatic mutations in the p53 gene and prognosis in breast cancer: a meta-analysis. Br J Cancer [Internet]. 1999 [acesso em 2015 nov 18];80(12):1968-73. Disponível em: http://www.ncbi.nlm. nih.gov/pmc/articles/PMC2363143/

25. Malta DC, Jorge AO. Análise de tendência de citologia oncótica e mamografia das capitais brasileiras. Ciênc Cult (São Paulo) [Internet]. 2014 [acesso em 2015 set 18];66(1):25-9. Disponível em: http://cienciaecultura.bvs. br/pdf/cic/v66n1/a12v66n1.pdf 
26. Instituto Nacional de Câncer. Açóes de enfermagem para o controle do câncer: uma proposta de integração ensino-serviço. 3a ed. Rio de Janeiro: Inca; 2008.

27. Vargens OMC, Bertero CM. Living with breast cancer: its effect on the life situation and the close relationship of women in Brazil. Cancer Nurs [Internet]. 2007 nov-dez [acesso em 2015 set 28];30(6):471-8. Disponível em: http://www. ncbi.nlm.nih.gov/pubmed/18025920

28. Pinto AC, Gióia-Martins DF. Qualidade de vida subsequente à mastectomia: subsídios para intervenção psicológica. Rev SBPH [Internet]. $2006 \mathrm{dez}$ [acesso em 2016 jul 6];9(2):3-27. Disponível em: http://pepsic.bvsalud.org/ $\mathrm{pdf} / \mathrm{rsbph} / \mathrm{v} 9 \mathrm{n} 2 / \mathrm{v} 9 \mathrm{n} 2 \mathrm{a} 02 . \mathrm{pdf}$

29. Höfelmann DA, Anjos JC. Autoavaliação de saúde e câncer de mama em mulheres de cidade do sul do Brasil. Rev Bras Cancerol [Internet]. 2012 [acesso em 2015 nov 18];58(2):209-22. Disponível em: http://www.inca.gov.br/ rbc/n_58/v02/pdf/11_artigo_autoavaliacao_saude_cancer_ mama_mulheres_cidade_sul_brasil.pdf

30. Almeida RA. Impacto da mastectomia na vida da mulher. Rev. SBPH [Internet]. $2006 \mathrm{dez}$ [acesso em 2015 nov 11];9(2):99-113. Disponível em: http://pepsic.bvsalud.org/ pdf/rsbph/v9n2/v9n2a07.pdf

31. Tavares JS, Trad LAB. Estratégias de enfrentamento do câncer de mama: um estudo de caso com famílias de mulheres mastectomizadas. Ciênc Saúde Coletiva [Internet]. 2010 jun [acesso em 2015 nov 18];15(Suppl 1):1349-58. Disponível em: http://dx.doi.org/10.1590/ S1413-81232010000700044

32. Wanderbroocke ACNS. Cuidando de um familiar com câncer. Psicol Argum. 2005;23(41):17-23.

33. Regis MF, Simóes MFS. Diagnóstico de câncer de mama, sentimentos, comportamentos e expectativas de mulheres. Rev Eletrônica Enferm [Internet]. 2005 [acesso em 2015 nov 2];7(1):81-6. Disponível em: https://www.fen.ufg.br/ fen_revista/revista7_1/pdf/ORIGINAL_08.pdf

34. Pinheiro CPO, Silva RM, Mamede MV, Fernandes AFC. Participating in a support group: experience lived by women with breast cancer. Rev Lat-Am Enfermagem [Internet]. 2008 Jul-Ago [acesso em 2015 nov 2];16(4):733-8. Disponível em: http://www.scielo.br/pdf/rlae/v16n4/13.pdf
35. Fernandes AFC, Mamede MV. Câncer de mama: mulheres que sobreviveram. Fortaleza: UFC; 2003.

36. Silva MRB, Borgognoni K, Rorato C, Morelli S, Silva MRV, Sales CA. O câncer entrou em meu lar: sentimentos expressos por familiares de clientes. Rev Enferm UERJ [Internet]. 2008 jan-mar [acesso em 2015 nov 2];16(1):705. Disponível em: http://www.facenf.uerj.br/v16n1/ v16n1a11.pdf

37. Bossois E, Gimenes FGO, Alves KR, Estevão MB, Paulino I. Sentimentos da mulher mastectomizada. Universo da Enfermagem [Internet]. 2013 [acesso em 2015 nov 2];2(1):5-19. Disponível em: http://novavenecia.multivix.edu.br/wp-content/uploads/2013/05/universo_enf_03.pdf

38. Toriy AM, Krawulski E, Vieira JSB, Luz CM, Sperandio FF. Percepçôes, sentimentos e experiências físicoemocionais de mulheres após o câncer de mama. Rev Bras Crescimento Desenvolv Hum [Internet]. 2013 [acesso em 2016 jul 6];23(3):303-8. Disponível em: http://pepsic.bvsalud.org/ pdf/rbcdh/v23n3/pt_08.pdf

39. Silva G, Santos MA. Estressores pós-tratamento do câncer de mama: um enfoque qualitativo. Rev Lat-Am Enfermagem [Internet]. 2010 jul-ago [acesso em 2015 oct 2];18(4). Disponível em: http://www.redalyc.org/articulo. oa?id=281421934005

40. Gobatto CA, Araujo TCCF. Coping religioso-espiritual: reflexóes e perspectivas para a atuaçáo do psicólogo em oncologia. Rev SBPH [Internet]. 2010 jun [acesso em 2016 jul 6];13(1):52-63. Disponível em: http://pepsic.bvsalud.org/ pdf/rsbph/v13n1/v13n1a05.pdf

41. Caetano EA, Gradim CVC, Santos LES. Câncer de mama: reaçóes e enfrentamento ao receber o diagnóstico. Rev Enferm UERJ [Internet]. 2009 abr-jun [acesso em 2015 out 2];17(2):257-61. Disponível em: http://www.facenf. uerj.br/v17n2/v17n2a21.pdf

42. Duarte TP, Andrade AN. Enfrentando a mastectomia: análise dos relatos de mulheres mastectomizadas sobre questôes ligadas à sexualidade. Estudos de Psicologia [Internet]. 2003 [acesso em 2015 nov 3];8(1): 155-63. Disponível em: http://www.scielo.br/pdf/epsic/ v8n1/17245.pdf

\section{Como citar este artigo:}

Cavalcante MLF, Chaves F, Ayala ALM. Câncer de mama: sentimentos e percepçóes das mulheres mastectomizadas. Rev. Aten. Saúde. 2016;14(49):41-52. 